\title{
A Matemática Escolar nas mudanças pedagógicas
}

\author{
The school Mathematics in the pedagogical changes
}

La Matemática escolar en las transformaciones pedagógicas

\author{
MARCUS ALDENISSON DE OLIVEIRA ${ }^{1}$
}

PINTO, Neuza Bertoni; VALENTE, Wagner Rodrigues (Orgs.). Saberes elementares matemáticos em circulação no Brasil: dos documentos oficiais às revistas pedagógicas, 1890-1970. São Paulo: LF Editora, 2016. 240f.

\footnotetext{
${ }^{1}$ Doutorando pelo Programa de Pós-Graduação em Educação e Saúde da Universidade Federal de São Paulo (Campus Guarulhos). E-mail: marcus_aldenisson@hotmail.com
} 
A obra "Saberes elementares matemáticos em circulação no Brasil: dos documentos oficiais às revistas pedagógicas, 1890-1970", organizada pelos pesquisadores Neuza Bertoni Pinto e Wagner Rodrigues Valente é fruto do projetão "A constituição dos saberes elementares matemáticos: a aritmética, a geometria e o desenho no curso primário em perspectiva histórico-comparativa, 1890-1970", financiado pelo CNPq. Trata-se de uma investigação coordenada pelo GHEMAT, mas é também desenvolvida mediante o envolvimento de duas dezenas de instituições de ensino superior e de diversos grupos de pesquisa de diferentes estados brasileiros - por isso, uso o termo projetão.

O livro é assim estruturado: apresentação, introdução e seis capítulos. De início, os organizadores apresentam ao leitor não só a obra propriamente dita, mas aquilo que no universo cinematográfico conhecemos como making-of, isto é, relatos dos bastidores, dos processos de escrita do livro, de cada capítulo. Em seguida, na introdução, Wagner Rodrigues Valente desperta a atenção do leitor logo no título com duas expressões: "dois e dois são sempre quatro" e "matemática do curso primário". Deve-se ler essas duas expressões com muito cuidado. Olhada numa perspectiva histórica, a disciplina Matemática tem os seus saberes presentes em diferentes matérias para além da Aritmética. E mais: para além da visão conteudista de que "dois e dois são sempre quatro" a epistemologia dos saberes matemáticos vai mudando ao longo do tempo. Isso pode ser lido e visto nos seis capítulos, os quais apresentam resultados das investigações de quarenta e oito pesquisadores, destacando justamente as transformações dos saberes matemáticos - o número de autores não é proporcional ao de capítulos, há variações.

De pronto, nota-se que o livro é fruto do trabalho da coletividade: duas pessoas para organizar, uma para fazer a introdução e quarenta e oito autores compuseram os capítulos. Não é muito comum reunir os resultados de estudos históricos com mais de quatro dezenas de pesquisadores num só livro. Não é tarefa fácil mobilizar várias mãos e mentes para um único objetivo: contar histórias da história da educação matemática das escolas primárias brasileiras, entre 1890 e 1970. Para acompanhar cada história narrada na obra supracitada o convite aqui lançado é lê-la utilizando um recurso bastante conhecido: o zoom, pois ele permite estabelecer movimentos de aproximação e afastamento. No primeiro movimento do olhar, a análise perpassa por cada capítulo, ou melhor, por cada história narrada buscando se aproximar de alguns detalhes dos eventos históricos (re)constituídos pelos autores. No segundo movimento, para tentar entender a filosofia de pesquisa dos membros do GHEMAT na produção dessa obra, a leitura parte de um "olhar de sobrevoo", isto é, me afasto das (re)constituições reflexivas dos eventos e examino o livro como um todo.

\section{O singular sendo plural: um tema (a Matemática escolar) e suas histórias...}

No capítulo 1, a expressão "lições de coisas" foi considerada correlato do ensino intuitivo. O fio condutor da escrita foi o manual de Calkins. Não o manual, propriamente falando, mas a concepção de ensino intuitivo por ele vulgarizada. Ao analisarem os programas de ensino da Bahia e do Paraná, os autores chegaram à conclusão de que há uma consonância entre as prescrições para o ensino dos saberes matemáticos dos 
programas e as propostas de estudo anunciadas nas páginas do referido manual. Embora haja elementos que indicam apropriações/ressignificações das propostas de Calkins, o manual do norte-americano foi pouco referenciado. Em relação ao exame dos programas de ensino de São Paulo, constataram-se que os saberes geométricos estavam presentes em diversas matérias: Desenho, Formas, Trabalhos Manuais, Geometria e Modelagem. Ainda assim, tais saberes, segundo os autores, "sofreram alterações em termos de metodologia, conteúdos, prescrições e finalidades". Concomitante a tais alterações, viu-se também o aparecimento paulatino dos materiais concretos e/ou ilustrados nas salas de aula. Esse foi um motivo da transformação do estatuto epistemológico dos saberes elementares matemáticos. Dois exemplos da Bahia são emblemáticos: o pedido de substituição das tabuadas por contadores ou numeradores; e a citação de um parecer emitido, em 1892, à Diretoria de Instrução Pública criticando a adoção de um livro de Desenho Linear por trazer, segundo o parecerista, inúmeras definições. Quais mudanças epistemológicas foram identificadas? Em tempos do ensino intuitivo, aprender a tabuada e os primeiros saberes de desenho seria partir do concreto para o abstrato, da intuição para a definição. O estudo concluiu que no ensino intuitivo a matemática do curso primário seria aprendida inicialmente como um saber sensivel: as lições deveriam começar pelas coisas e não por definições.

O capítulo 2 tem na escrita uma proposta metodológica interessante. Acompanhem. O ensino de desenho nas escolas primárias, entre 1890 e 1930, caracterizou-se por duas dinâmicas: discursos internacionais que foram apropriados no país (São Paulo e Rio de Janeiro, especificamente) e a circulação das ressignificações de tais discursos nos diferentes estados. Nas análises das revistas pedagógicas brasileiras, identificaram-se discursos vindos de Portugal, Espanha, Bélgica, França que propagavam "modelos de ensino" para o saber desenho. No interior de tais modelos havia uma dualidade de método de ensino: o método geral e o método de desenho geométrico. Essa dualidade foi caracterizada no cenário estrangeiro e espalhou-se pelo território brasileiro. O impacto das ressignificações desses discursos no âmbito nacional pôde ser evidenciado a partir do cruzamento das propostas de ensino de desenho presentes nas revistas e nos programas. Constatou-se que a dualidade se caracterizou não só em termos de método, mas de saberes. Isto é, as diferentes finalidades das escolas primárias de São Paulo, Sergipe, Santa Catarina e Paraná colocaram na ordem do dia novas imputações para o ensino de desenho: ora um saber desenhar à mão livre, ora um saber desenhar aparelhado com os instrumentos (régua, compasso, esquadro e transferidor). $\mathrm{O}$ estudo revelou que com essas exigências o próprio saber escolar desenho acabou sendo agregado a diferentes rubricas do curso primário: Desenho, Desenho Linear, Desenho Natural, Geometria, Trabalhos Manuais. Nas entrelinhas, a investigação ainda apontou que as ressignificações dos ideais internacionais para o saber desenho foram contornadas pelas descontínuas trajetórias. Os meios de circulação e a época do desembarque dos ideais estrangeiros em São Paulo, Sergipe, Santa Catarina e Paraná interferiram nas ressignificações. Em síntese: quis-se mostrar que uma recomendação para o ensino de desenho teve apropriações distintas, por isso a necessidade de ser compreendida no seu espaço recepção. 
O capítulo 3 também mostra que as finalidades da Aritmética do curso primário impulsionaram a transformação e a emergência de saberes. Temporalmente delimitado de 1925 a 1970, o estudo sublinha a pulverização de métodos de ensino presentes nos movimentos pedagógicos da Escola Nova e da Matemática Moderna. A partir das análises de artigos publicados em revistas pedagógicas e de programas dos estados de Minas Gerais, São Paulo, Paraná e Rio Grande do Sul, identificaram-se duas recomendações distintas para o ensino da Aritmética. A título de exemplo, destacou-se o ensino de "resolução de problemas". Diferentes métodos demandaram dois saberes: um saber resolver os problemas e um saber pensar os problemas. Parecem ser os mesmos saberes, mas só parecem! De acordo com os autores, no período da Escola Nova uma das finalidades da Aritmética era a de preparar o aluno para a vida. Com isso, "um bom problema seria aquele que oferecesse utilidade, reproduzisse situação da realidade do aluno, $[. .$.$] ". Se um dos princípios escolanovistas era que a criança aprendesse por si, então$ o que se exigia era um saber resolver os problemas da sua vida cotidiana. Por consequência, isso caracterizava a própria utilidade da Aritmética escolar. Já no Movimento da Matemática Moderna, a teoria do desenvolvimento humano de Piaget considerou insuficiente apenas resolver os problemas da vida cotidiana, tinha-se que raciociná-lo como um todo: identificar as possibilidades do uso de material auxiliar para a execução das operações; apresentar a solução mais econômica; enfim, reivindicava-se que a criança soubesse pensar o problema, pois "a finalidade da escola [primária] em geral é ensinar a pensar e não a memorizar".

O capítulo 4 tem "a resolução de problemas" como temática. Mais especificamente, analisam-se as concepções de problemas aritméticos e geométricos presentes em artigos de revistas pedagógicas que circularam nas Alagoas, Bahia e Rio Grande do Sul, entre 1920 e 1960. O que se vê é um repertório de tipologias e de orientações metodológicas para a resolução de problemas matemáticos na escola primária. Com isso, adotou-se por objetivo identificar referências de intelectuais que defendiam os ideais escolanovistas nas orientações metodológicas para elaboração e/ou resolução de problemas. Em alguns casos, as referências já eram mencionadas ao longo dos artigos das revistas. Noutros, as referências foram identificadas a partir de um cruzamento entre as orientações presentes nos artigos e os textos de teóricos amplamente utilizados na Escola Nova, a exemplo de Thorndike. Essa operação sistemática com os dados empíricos configura a originalidade metodológica do capítulo. Vale destacar ainda que ao longo de toda análise os autores não perderam de vista duas questões: 1) o que se entendia como um problema? 2) como um problema era anunciado: com objetos concretos? com algarismos? As respostas variaram. $\mathrm{Na}$ Bahia, por exemplo, em 1927, a professora Julia Leitão indicou que um problema para ser atraente teria que começar com objetos concretos. No Rio Grande do Sul, em 1958, Rosalvo Torres disse que os problemas deveriam ser adequados para a escola rural. Quis-se enfatizar que a concepção do que se entendia por um problema e de como ele deveria ser anunciado dependeria da finalidade posta à escola. As características sociais, políticas e econômicas muito diferentes entre os estados também contribuíram para melhor acompanhar a velocidade histórica das mudanças e das continuidades. Isso mesmo, os 
autores notaram que mesmo dentro de um território (o Brasil) as mudanças históricas podem ser lentas, rápidas, não uniformes, contínuas e descontínuas. A tipologia do que era um problema não se alterou de forma linear nas Alagoas, Bahia e Rio Grande do Sul.

No capítulo 5, o olhar é deslocado do curso primário para o curso normal. Mas o alvo continua o mesmo: a matemática, agora aquela da formação dos professores. A análise da legislação educacional (dos programas de ensino, especificamente) dos estados de Minas Gerais, Rio Grande do Sul, Espírito Santo, Mato Grosso, Paraná e São Paulo possibilitou a identificação de uma cisão na formação dos professores. Trataram-se de dois corpus de saberes de naturezas distintas: os científicos e os pedagógicos. No início do séc. $\mathrm{XX}$, nas Escolas Normais, a formação era de cunho científico, ou seja, as disciplinas impetravam do professor um saber: saber aplicar. A partir da década de 30, com o aparecimento dos Institutos de Educação, a formação teve caráter pedagógico, isto é, as disciplinas requisitavam do professor um saber específico: saber ensinar. Nessa levada, a disciplina Práticas de Ensino teve papel importante. Essa sútil distinção entre os saberes pode ser melhor exemplificada da seguinte maneira: do ponto de vista científico, a teoria prevalece em relação à prática, pois a atividade escolar tem em si o seu valor representativo; do ponto de vista pedagógico, a prática sobrepuja a teoria, pois o momento pedagógico do ensinar requer atenção ao desenvolvimento do aluno (a criança). Nessas duas perspectivas, qual o lugar dos saberes matemáticos? Ao longo do capítulo fica evidente que os saberes matemáticos estiveram presentes em vários lugares, ou melhor, em várias disciplinas. Numa formação mais científica, propriamente falando, os saberes matemáticos puderam ser identificados nas disciplinas: Aritmética, Álgebra, Desenho, Desenho Geométrico, Desenho Ornato, Desenho Topográfico, Geometria, Trabalhos Manuais. Com a formação mais pedagógica, a matemática esteve presente nas disciplinas: Metodologias, Matérias de Ensino, Práticas de Ensino. É claro que essa estrutura curricular não foi a mesma nos cursos de formação dos professores dos estados envolvidos na pesquisa. Foi justamente para acentuar tais diferenças na formação dos professores que 11 pesquisadores se lançaram a cruzarem os resultados de suas investigações. Para além de qualquer conclusão parcial, é imprescindível notar que as disciplinas mesmo aquelas da formação dos professores não são constituídas em um corpo homogêneo de saberes.

O capítulo 6 apresenta uma interessante perspectiva de análise dos saberes elementares matemáticos. Ao longo do texto, os autores acentuaram as continuidades nas mudanças. Isso mesmo, continuidades nas transformações. Delimitada entre os anos de 1930 a 1970, a análise inicial de um corpus de artigos de revistas pedagógicas indicou a necessidade de que para melhor compreender as transformações da matemática escolar seria preciso justapor os ideais das pedagogias intuitiva e escolanovista. Aqui tem início a perspectiva de análise que me refiro: justapor ideais pedagógicos e não sobrepô-los. $\mathrm{O}$ Sistema de Numeração Decimal (SND) foi o saber escolar privilegiado para acompanhar suas transformações. A partir de cruzamentos das análises realizadas em revistas pedagógicas, livros didáticos, manuais pedagógicos e programas de ensino, foi "possível encontrar aspectos do método intuitivo concomitante a outros métodos da Escola Nova". Mais que isso, ao se enveredarem pela trajetória profissional dos autores dos livros 
didáticos e manuais pedagógicos, constatou-se também a emergência de um grupo de experts que propuseram "modelos" de ensino do SND. Cada modelo caracterizou um saber para o estudo do SND. Em tempos da pedagogia chamada de tradicional, clamou-se por um saber inteligível cadenciado pela ordem interna do próprio sistema de numeração, isto é, uma ordem lógica (a memorização desempenhava papel fundamental). Com a pedagogia intuitiva, exigiu-se um saber sensivel, ou seja, a experiência como ponto de partida do saber (os sentidos tinham valor supremo). No movimento da Escola Nova, requisitou-se um saber sob medida, em outras palavras, a psicologia experimental daria o diagnóstico do desenvolvimento intelectual da criança (o saber escolar era condicionado pelos resultados dos testes psicológicos). Por fim, os autores do capítulo encerram a escrita deixando a mensagem: "Que esse nosso olhar possa abrir novos caminhos sobre o tema". Pergunteime: que olhar? Só obtive a resposta quando tornei a ler o capítulo: um olhar de que a pesquisa histórica não só analisa os fatos, mas os reconstituem por meio da problematização que modifica a interpretação e explicação dos fatos. Tal é o exemplo da identificação de um grupo de experts!

$$
* * *
$$

Após essa passagem de capítulo em capítulo, o livro apresenta-se como uma "caixa de ressonância" das inquietações que mobilizam algumas pesquisas dos membros do GHEMAT. Como um todo, o livro deixa às claras que tais inquietações se deslocam para um objetivo bem definido: compreender a trajetória de constituição dos saberes elementares matemáticos quer os do curso primário quer os do curso de formação de professores, entre 1890 e 1970. Para o alcance disso, os pesquisadores do GHEMAT veem fazendo o seguinte dever de casa: acentuando as mudanças de tais saberes ao longo do tempo. Nesse aspecto, não seria muito considerar que os seis capítulos estampam as matérias e/ou disciplinas escolares como camaleões, isto é, as rubricas recebem os "tons" de mudanças pedagógicas de cada tempo e tornam-nos visíveis. No caso particular do livro lançado, o tópico abaixo objetiva revelar fatores comuns que possibilitaram os autores tornarem visíveis algumas mudanças nos saberes elementares matemáticos, no período estudado.

\section{Recursos utilizadas pelos autores para fazer do livro um trabalho da coletividade}

O que seis capítulos e quarenta e oito autores podem apresentar em comum na produção do livro Saberes elementares matemáticos...? Resposta: vários fatores. Destaco apenas três, os quais no meu entender revelam a filosofia de trabalho do GHEMAT na produção dessa obra. O primeiro deles é a necessidade de pelo menos um coordenador por cada subgrupo formado a partir de uma temática específica. O próprio sumário revela isso, pois cada capítulo tem ao menos um coordenador.

O segundo fator é o uso do Repositório ${ }^{2}$ de conteúdo digital como espaço privilegiado de busca das fontes. Trata-se de um arquivo virtual constituído por documentos textuais (legislação educacional, livros didáticos, revistas pedagógicas, etc.) e

2 Acessível em: <https://repositorio.ufsc.br/handle/123456789/1769>. Para saber mais sobre o Repositório vede Costa e Valente (2015), Costa (2015). 
iconográficos (fotos de instrumentos utilizados pela escola, por exemplo a palmatória e a lousa de pedra). Para além do que se possa pensar, atualmente o Repositório não é somente mais um arquivo que salvaguarda um conjunto de documentos que tem datas, formas e suporte material específico. Por ser digital, esse tipo de arquivo configura algumas rupturas: não se tem mais um horário fixo para o pesquisador examinar as fontes, pois elas estão disponíveis 24 horas por dia; não se faz mais fotocópias ou fotografias das fontes, é só fazer downloads; não se tem mais uma sala de leitura fixa, pois o pesquisador pode salvar o documento num netbook, tablet ou e-reader e lê-lo onde e quando quiser, a exemplo no metrô (em contrapartida, o silêncio da sala de leitura é rompido!); enfim, outras rupturas poderiam ser aqui citadas. Porém, é válido mencionar mais uma delas. Trata-se do acesso imediato ao documento analisado pelo pesquisador. Ou seja, o leitor pode julgar as interpretações que os autores fizeram aos documentos utilizados para compor cada capítulo do livro em questão. O GHEMAT lança um livro que proporciona um desencaixe na leitura: o leitor tem a oportunidade de ler uma representação dos fatos históricos construída em cada capítulo e, sem intermediário, ele próprio pode analisar os mesmos fatos históricos e construir a sua representação. A propósito, esta resenha não é mais do que a uma representação construída a partir do livro "Saberes elementares matemáticos..."

O terceiro e último fator comum presente nos seis capítulos é o fazer historiográfico propagado pela História Cultural como suporte teórico-metodológico. Os autores do livro se amparam em pelo menos um critério dessa corrente historiográfica (a criticidade dos fatos pelo viés teórico) e contam histórias da história da educação matemática. Quando digo contam histórias não se deve entender narram histórias no sentido apregoado pelo Historicismo Alemão - o de uma história factual; isto é, uma história "[...] que se compraz em meramente encadear os fatos [...]" (BARROS, 2012, p. 69). Diferentemente desse entendimento, a meu juízo, os autores do livro contam histórias a partir da análise dos fatos e das ações de alguns personagens envolvidos no contexto da configuração dos fatos - mais do que enfileirados em séries, os fatos foram problematizados, interpretados e entrelaçados numa narrativa histórica. De acordo com Peter Burke (2012, p. 249), essa forma de narrativa histórica poderia ser denominada de "narrativa 'tramada', pois ela entrelaça a análise [dos fatos] com a arte de contar histórias". Assim, guiados pela História Cultural, é como se os quarenta e oito autores do livro quisessem "gritar": a narração de uma história exige a teorização dos fatos; uma história-problema não se contenta com a reconstituição exata do passado (como pensam os historiadores chamados de positivistas), mas de um conhecimento histórico que é reflexivo no qual os fatos do passado são interrogados, analisados e explicados por uma narrativa.

\section{$* * *$}

De um modo geral, o livro constitui-se em verdadeiro mapeamento de modelos, de padrões pedagógicos que viajaram o Brasil afora, entre 1890 e 1970, os quais foram ora instaurados (por força da lei) ora criados (por força das táticas) para o ensino dos saberes elementares matemáticos quer no curso primário quer na formação dos professores. Como leitor, usei o livro para fazer a seguinte pergunta aos quarenta e oito autores: no fundo, o que vocês quiseram me dizer nos seis capítulos? Foi como se eles respondessem todos ao mesmo tempo numa só voz, dizendo: entre 1890 e 1970, os saberes elementares 
matemáticos estiveram em movimentos (mudanças) incessantes, organizaram-se também de acordo com a geografia da circulação e os modos de apropriação.

\section{Referências}

BARROS, José D'Assunção. Teoria da história: a Escola dos Annales e a Nova História, vol. V. Petrópolis, RJ: Editora Vozes, 2012.

BURKE, Peter. História e teoria social. Tradução Klauss Gerhardt, Roneide Venâncio Majer e Roberto Ferreira Leal. 3. ed. São Paulo: Editora Unesp, 2012.

COSTA, David Antonio. Repositório. In: Valente, Wagner Rodrigues (Org). Cadernos de Trabalhos. 1. ed. São Paulo: Editora Livraria Física, v. 3, p. 1-50, 2015.

COSTA, David Antonio; Valente, Wagner Rodrigues. O uso do repositório de conteúdo digital nas pesquisas de história da educação matemática. Revista Ibero-americana do Patrimônio Histórico-Educativo. São Paulo: Campinas, v. 1, p. 94-108, 2015.

PINTO, Neuza Bertoni; Valente, Wagner Rodrigues. (Org.). Saberes elementares matemáticos em circulação no Brasil: dos documentos oficiais às revistas pedagógicas, 1890-1970. São Paulo: LF Editora, 2016. 